\title{
Spina Bifida and craniocervical junction anomaly. A case report
}

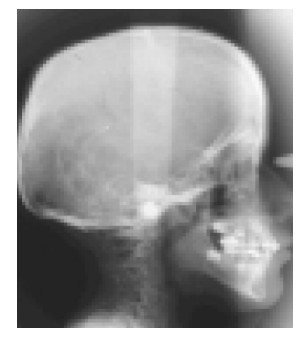

\author{
Zahia VERNEX-BOUKERMA, Pierre CORRE, \\ Jean-Philippe PERRIN, Roman Hossein KHONSARI, \\ Jacques MERCIER, Jean-Michel SALAGNAC
}

ABSTRACT

\section{Introduction}

Spina bifida is a rare congenital disorder due to a closure anomaly of the neural tube.

\section{Clinical case}

A 9 years-old girl presents with lumbar spina bifida aperta and cervical spina bifida occulta. Her case illustrates the importance of orthodontic xrays in the diagnosis of cervical spine malformations.

\section{Discussion}

There are two categories of spina bifida.

When refered to as aperta, the disorder associates a dorsal vertebral bony gap and an involvement of the spinal cord. A skin pouch can form and include meninges alone (meningocele) or meninges with spinal cord (myelomeningocele). Spina bifida is generally located in the lumbar or sacral regions, and extends over 2-3 vertebrae.

On the other hand, the involvement of the cervical spine is often of the occulta type, where the defect is covered by skin and is limited to the bone.

This rare condition cannot be ignored by the clinician as the craniocervical junction anomalies induced by this malformation can be associated with C1-C2 instability, as in our case report.

\section{KEYWORDS}

Spina bifida aperta

Spina bifida occulta

Arnold-Chiari malformation

Craniocervical junction anomaly

Address for correspondence:

Z. VERNEX-BOUKERMA

Clinique de chirurgie maxillofaciale et stomatologique,

CHU,

1, place

Alexis Ricordeau 44093

Nantes Cedex 1.
Meningocele

Myelomeningocele

C1-C2 instability. 


\section{1 - INTRODUCTION}

Spina bifida is a disorder in the closure of the neural tube. The aperta form associates a dorsal vertebral bony gap with an involvement of the spinal cord. A skin pouch can form and include meninges alone (meningocoele) or meninges with spinal cord (myelomeningococele). Spina bifida predominates in the lumbar or sacral regions, and extends over 2-3 vertebrae. The clinical severity of the lesion depends on the involvement of the spinal cord.

\section{2 - CASE REPORT}

A 9-years old girl (fig. 1 a, b, c) was referred to our department for the extraction of teeth 14, 24, 34 and 44 in the course of her orthognatic treatment. She suffered from a major dental crowding interfering with normal canine growth (fig. 1 c, fig. 2).

Facial and lateral cephalometric X-rays (fig. 3) and a orthopantomo-
Spina bifida in the cervical spine is generally of the occulta form. The gap is then limited to the bone. The diagnosis of the malformation is often made by chance, when the C1-C2 instability resulting from the craniocervical junction anomaly induces the apparition of neurological signs.

Our case report is the occasion to insist on the fact that this malformation can be also diagnosed with standard orthodontic X-rays. gram (fig. 2) were realized and studied by the orthodontist; the patient was sent to the maxillofacial surgeon to realize the extraction. Surgical decision of the extraction was done after examination of the case.

This young patient is also followed up by a child orthopedist. At 24 hours of age, she was operated for a lumbar

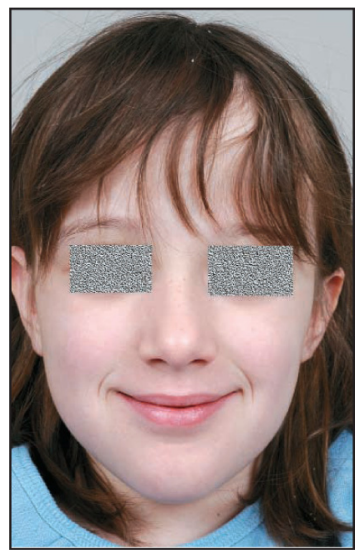

a

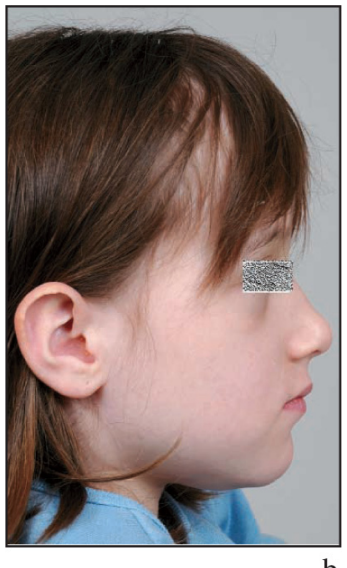

Figures 1 a to $c$

Young patient, 9 years-old.

a: full facial view; b: profile view: good facial balance; c: front view of occlusion: dental crowding. 


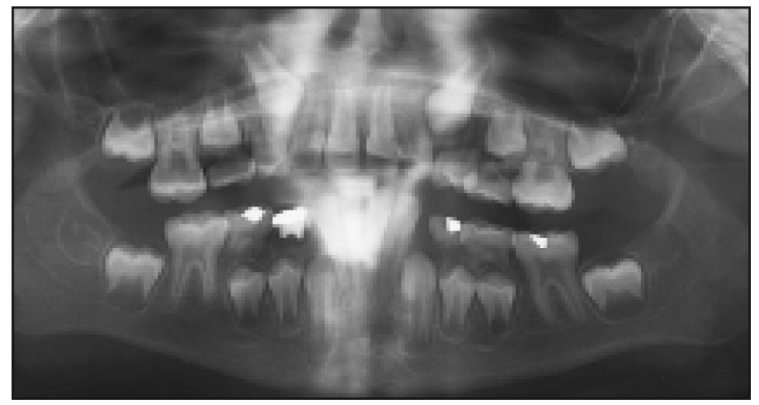

Figure 2

Orthopantomogramm showing 4 cuspids blocked by the first bicuspids.

spina bifida aperta and still carried a ventriculo-atrial shunt for hydrocephaly. The patient depends on a wheelchair for her movements and cannot stay seated with the neck extended for a long period. In her first years of life, she also benefited from talipes surgery, numerous varisation osteotomies of her knees and dorsal relaxation for scoliosis. She furthermore suffers from an allergy to latex.

The extractions proposed by the orthodontist where part of a treatment plan designed to be as light as possible, to avoid any excessive medical care.

The observation of the orthodontic cephalometric X-rays and of the orthopantomogram performed by the orthodontist led us to fear a craniocervical junction anomaly. In fact, the processus spinosus of C2 was doubled; furthermore, the hypoplastic odontoid (fig. 3, fig. 5 a), was fused with the occipital bone and a C1-C2 spondylolysthesis suggesting a C1-C2 instability or C1-occipital instability. Thus, and before any chirurgical act we have requested a neurosurgeons staff to screen any neurologic lesion.

They proceed to dynamic cervical spine xrays in flexion and extension (fig. 4) to screen C1-C2 instability. They found a rise of C1-C2 spondy-

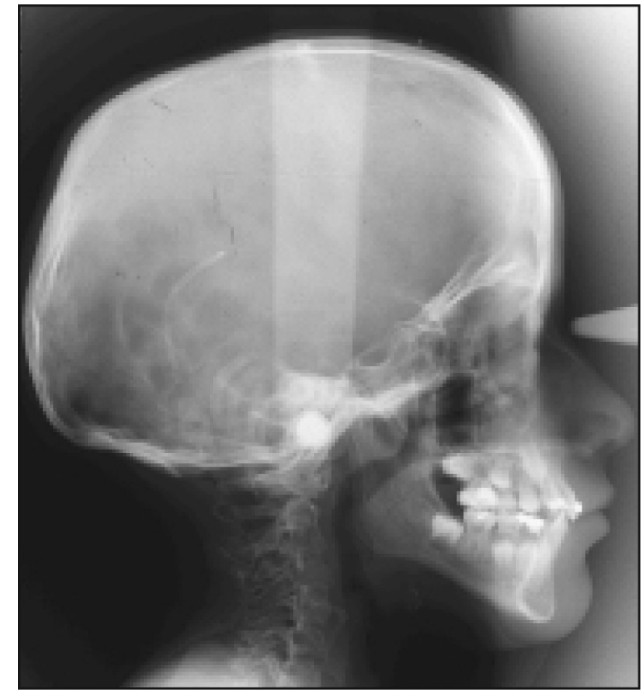

Figure 3

Lateral cephalograph showing ventrioatrial shunt and C1-C2 spondylolysthesis.

lolysthesis but the junction was nevertheless stable.

CT-scan in osseous window with reconstructions in all plans was performed (fig. 5 a to c) to appreciate the impact on bone structure. It confirmed doubled processus spinosus, hypoplastic odontoid fused with the occipital bone, and showed an os odontoidum (sesamoid bone of axis) and posterior and anterior arch agenesy of atlas which having for consequence a space of the lateral mass.

$\mathrm{MRI}$, which is the best examination to study medullar anomalies (fig. 6 a and b), diagnosed a cervical spina bifida occulta and a hydrocephaly due to an Arnold-Chiari malformation type II. The patient didn't exhibit any neurological focal signs of syringomyelia and the hydrocephaly was well controlled by the shunt.

No cervical surgery was performed regarding the stability of the junction. The extractions could thus 

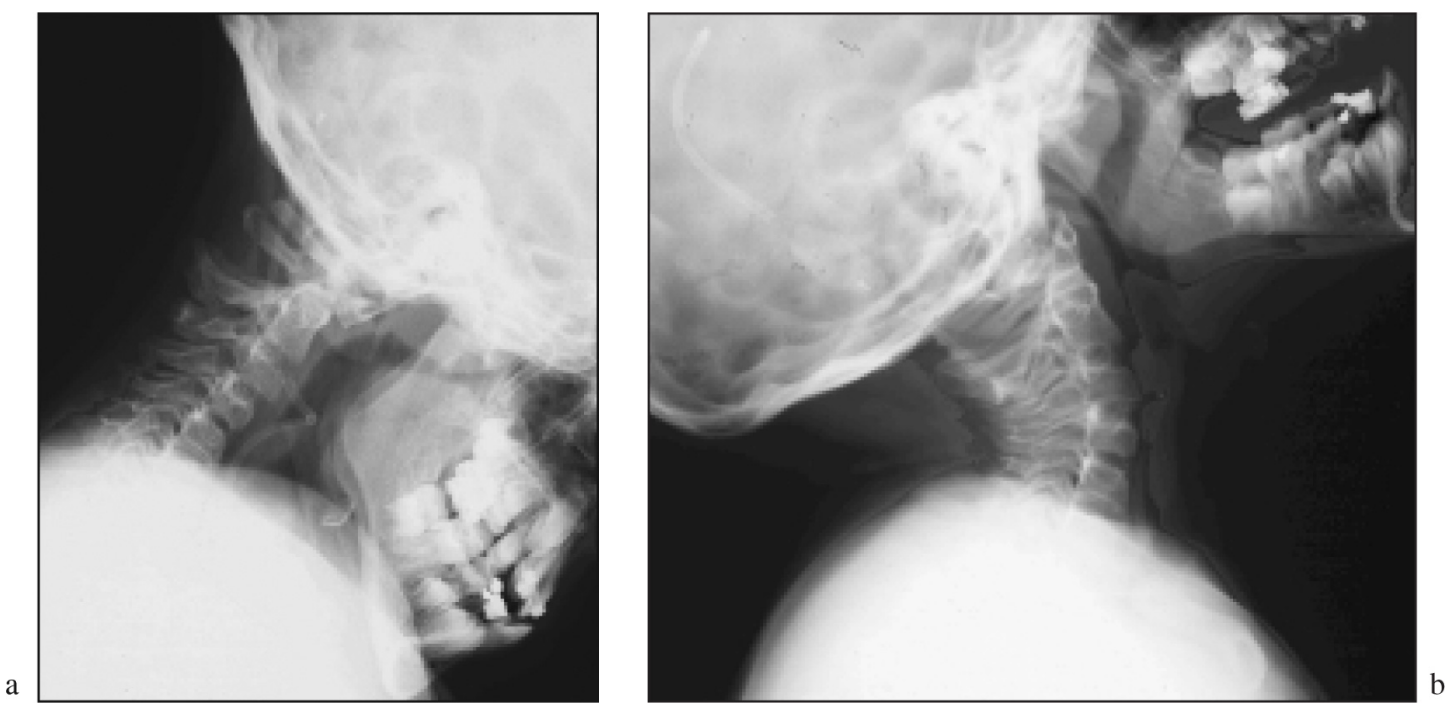

Figures $4 a$ and $b$

a: dynamic cervical lateral $X$-rays in forced flexion: rise of C1-C2 spondylolysthesis;

b: dynamic cervical spine $X$-rays in forced extension.

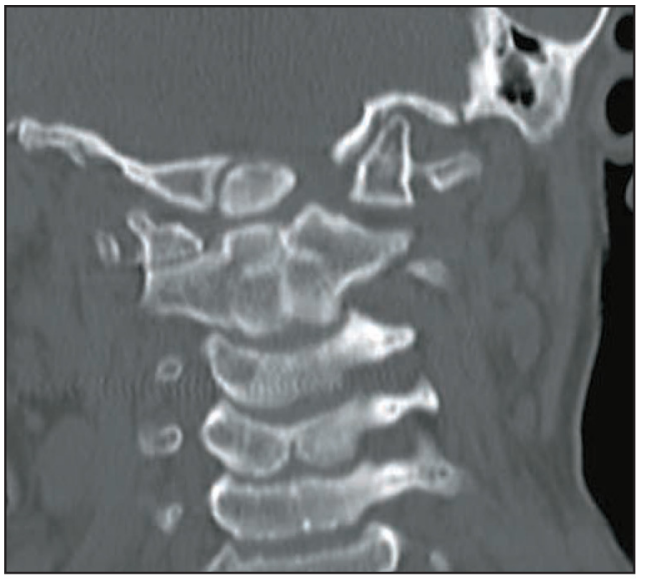

a

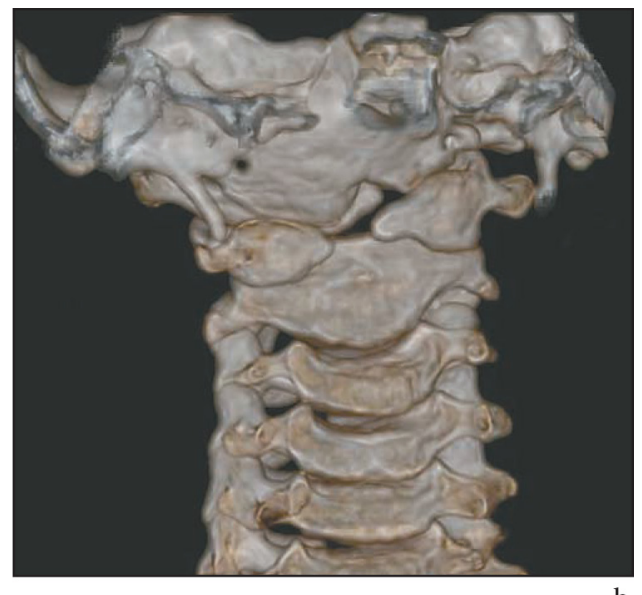

$\mathrm{b}$

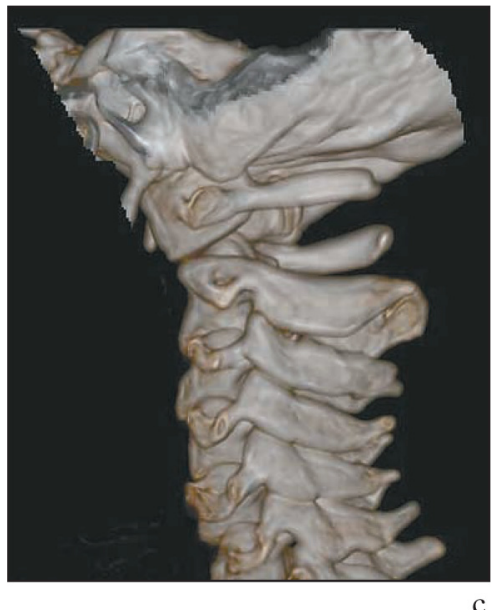

$\mathrm{c}$

Figures 5 a to $c$

CT-scan imaging.

a: frontal CT reconstruction: os odontoïdum and double processus spinosum in C2;

$b$ : facial view of the $3 D$ reconstruction: agenesis of $C 2$ anterior and posterior arches;

c: lateral view of the 3D reconstruction: processus spinosum pf $\mathrm{C} 1$ and $\mathrm{C} 2$ are apart with spondylolysis in neutral position.

be performed without compressive risks on the cervical spinal cord during the forced neck extension.
On orthopantomogramm (fig. 2), teeth 13 and 23 were blocked by 14 and 24. Teeth 55 and 65 were present, 

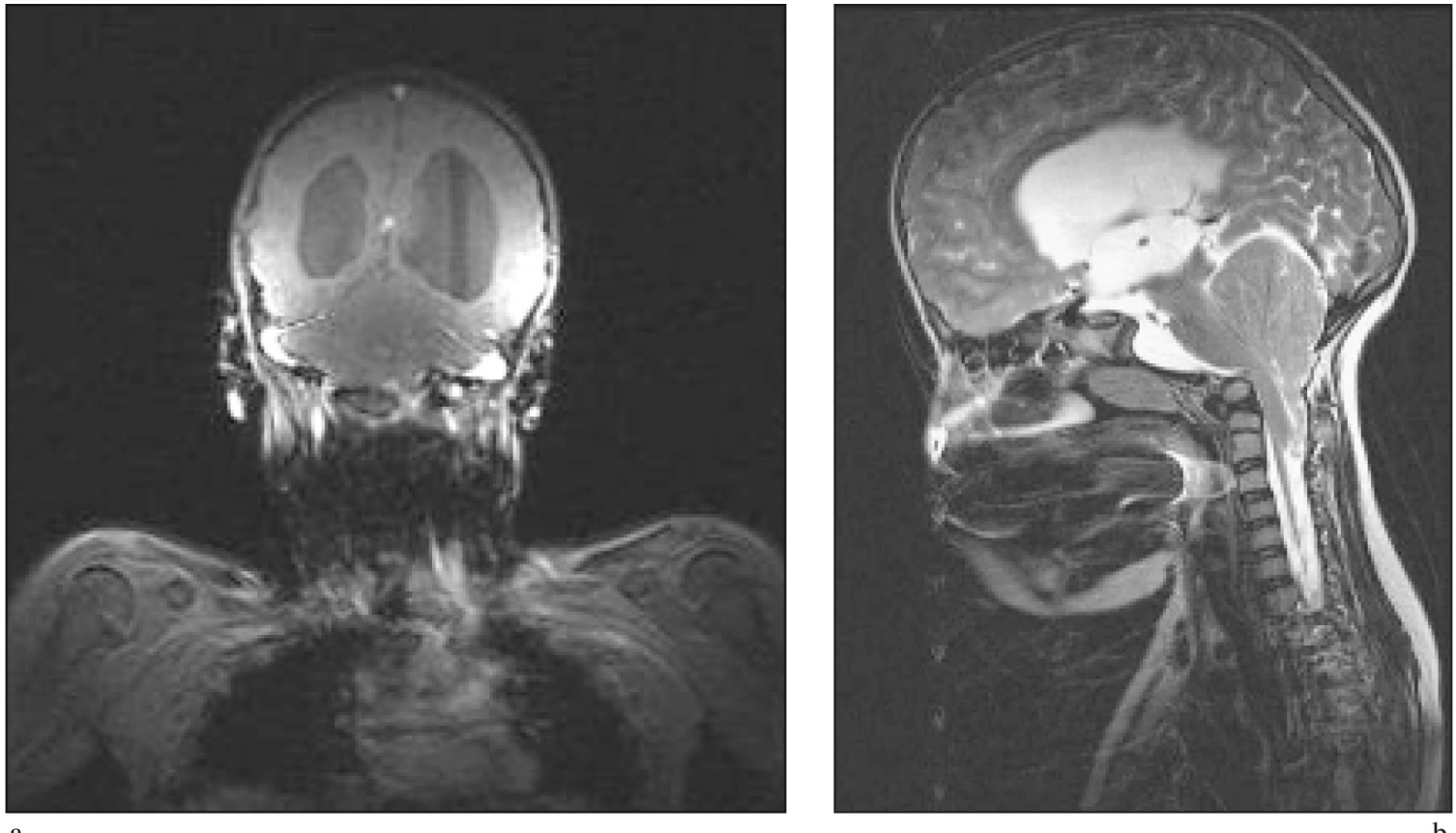

Figures $6 a$ and $b$

Magnetic resonance imaging.

a: coronal view: major residual hydrocephaly despite the shunt;

$b$ : lateral view: widening of the magnum foramen with protrusion of the medullar bulb into the spinal canal: Arnold Chiari type II malformation.

as well as the germs of 15 and 25 . Germs of teeth 34, 35, 44, 45 were present over temporary dentition and 33 and 34 couldn't grow properly because of the major dental crowding. Because of the absence of

\section{3 - DISCUSSION}

Spina bifida is a latin term which refers to a posterior opening in the ver- tebrae associated to a spinal cord involvement. Spina bifida results from a neural tube closure anomaly (incomplete closure of posterieur vertebral arch) associated with lesion of spinal $\operatorname{cord}^{4,12,13,15}$. It is due to embryological anomaly occurred in the 4th week. It is generally located in the lumbar or mandibular premolar growth, we decided to extract teeth 14, 24, 84 and 74 under local anaesthesia.

The patient is currently following her orthodontic treatment.

sacral regions and extends over 2-4 vertebrae. In France, 0.5/1000 children present this malformation10, more frequent in AngloSaxon countries with 8/1000 and 2/1000 in U.S.A ${ }^{13}$. More precisely, spina bifida would be the result of a disorder in the metabolism of folates. Several genes are thought to be responsible of the malformation, such as the 
MTHR (methylen tetrahydrofolate reductase) gene located in 1 p36.3 $3^{13,17}$ or PAX3 structure gene ${ }^{14}$. Zinc metabolism has also been incriminated. The syndromic cases, especially those resulting from chromosomal anomalies (trisomia 18 for instance, triploidy) ${ }^{10}$ are generally lethal. Folic acid treatment during pregnancy seems to lower the rate of neural tube closure anomalies 6,13-15.

This malformation can be exteriorized: aperta form (fig. 7); or closed: occulta form (fig. 7) where the spinosus processus is doubled but covered with skin.

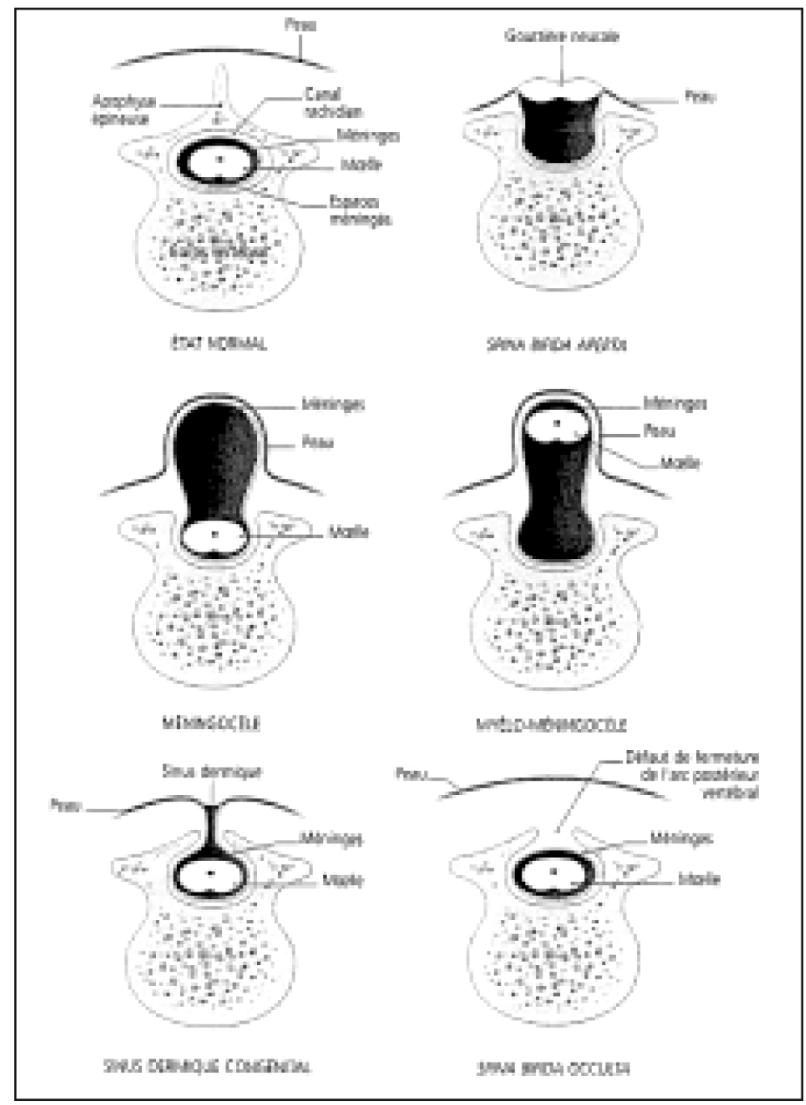

Figure 7

Figures showing different types of spina bifida ${ }^{4}$.
Two main anatomical presentations of Spina Bifida Aperta are described with several severity:

- Meningocoele is the less frequent but also the less severe form. The skin pouch adjacent to the spinal bony defect only contains meninges. The spinal cord stays in its normal location and the spinal nerves are not damaged.

- Myelomeningococele (fig. 8) is more severe and unfortunately includes $75 \%$ of spina bifida cases. The spinal cord and the spinal roots are exposed through the spinal bony gap, generally without any skin cover because of agenesy of the posterior arches. When the protruding spinal cord is covered by a thin layer of leptomeninges, the anomaly is referred to as spina bifida cystica.

Spina Bifida Aperta is often associated, as in our case, with an ArnoldChiari type II anomaly, characterized by a misposition of the bulbar region of the brainstem and of the cerebellum. In fact, these structures can be

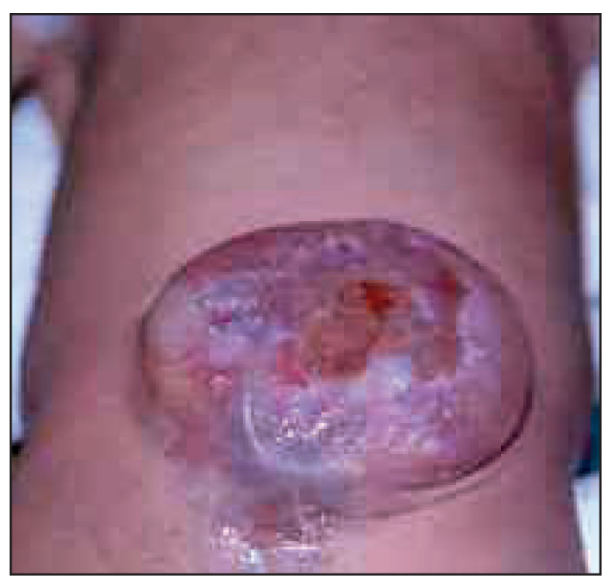

Figure 8

Dorsal view of a new-born child with lombo-sacral myelomeningococele. 
situated as low as C3 when they should be enclosed in the skull2,6,9,12-14. Arnold-Chiari type II anomaly is a major cause of hydrocephaly due to bad circulation of cerebrospinal fluid or defect of absorption.

The prenatal ultrasound diagnosis of spina bifida can be done as soon as the 11th week of life. The typical echographic signs of spina bifida are: hydrocephaly, feet anomalies (such as talipes) and lack of normal mobility in the lower limbs. Such signs lead to perform an amniocentesis and look for biological stigmata of spinal canal opening such as the rising of alphafoetoprotein rate in the cerebrospinal fluid.

The treatment of spina bifida is an emergency and has to be performed in the 24-48 hours following delivery. The technique involves the exploration of the skin pouch and the close of the meningeal opening. The patient can be shunted simultaneously, or more frequently secondarily if the hydrocephaly is not severe. Foetal surgery may be the future treatment standard ${ }^{13}$.

Clinical signs reflect the severity of the spinal cord involvement: paraplegia, urinary and/or anal incontinence, dorsolumbar scoliosis, genito-sexual disorders, talipes, an allergy to latex probably due to the great number of surgeries $2,13,14$.

In the particular case of spina bifida occulta, the anomaly is often discovered by chance. Hair on the back midline is a classical sign of spina bifida ${ }^{4,15}$. Less frequently, the patients can report back pain or develop focal neurological signs ${ }^{1,716}$. The most frequent localizations of the occulta form are $\mathrm{C} 1$ and $\mathrm{C}^{9}$.
Our patient had a lumbar myelomeningocoele, a C1 spina bifida occulta with anterior and posterior arch agenesis, a doubled C2 processus spinosus, a dens hypoplasy and an odontoïdum bone (sesamoid bone).

Such malformations can mimic the symptoms of a narrow cervical canal (see the case of a children 8 old of Connor et al. ${ }^{5}$, present as a C1-C2 instability or lack any clinical manifestation). Cervical myelopathy due to Spina Bifida Occulta is very rare ${ }^{1}$. It results from a compression of spinal cord by invagination of doubled spinosis processus and $\mathrm{C} 1-\mathrm{C} 2$ instability?

In the cases without clinical manifestations, minor trauma or excessive cervical extension can induce the apparition of acute focal neurological signs.

Standard cervical spine X-rays are a good source of information for this kind of anomalies ${ }^{3}$. Interestingly, isolated cervical spondydolisthesis is not frequent in children and generally predominates on $\mathrm{C}^{8}$. Surgery such as arthrodesis is generally not required for this localization but only in case of pain or focal neurological signs.

Down's syndrome (trisomy 21) can be associated with $\mathrm{C} 1$ spina bifida occulta without systematic $\mathrm{C} 1-\mathrm{C} 2$ instability ${ }^{7}$.

In all cases where a spinal cord compression is suspected, CT-scan (for the visualization of the bone lesions) and actually whith the technology of multislice X-ray computed tomography (provided excellent 3D reconstruction), and $\mathrm{MRI}$ (for the cord and diagnosis of narrow cervical canal) are mandatory ${ }^{3,11}$. 


\section{4 - CONCLUSION}

Spina bifida is not familiar to orthodontists and maxillofacial surgeons. Nevertheless, as the upper cervical spine is visible on standard orthodontic X-rays, we should systematically look for such malforma- tions, even when no neurological signs are reported. Early screening is essential because a lot of cephalometric X-rays are processed by the orthodontist on very young patients.

\section{REFERENCES}

1. Asakawa HYK, Narushima K, Meguro K, Nose T. Anomaly of the axis causing cervical myelopathy. Case report. J Neurosurg 1999;91:121-3.

2. Chester HHoMDWL-A, Priebe MD, Chiodo AE, Scelza MD, Kirshblum S. Spinal Cord Injury Medicine. Epidemiology and Classification. Archives of physical Medicine and Rehabilitation 2007;88:S49-S54.

3. Chevrot ADJL, Dupont AM. Imagerie du rachis cervical douloureux. J Radiol 2003;84:181-239.

4. Cochard Larry L. Atlas d'embryologie humaine de Netter. Paris : Masson, 2003.

5. Connor JCC, Robinson S, Jarosz JM. Congenital midline cleft of the posterior arch of atlas: a rare cause of symptomatic cervical canal stenosis. Eur Radiol 2001;11:1766-9.

6. Czeizel AE. Prevention of Neural Tube Defects. CNS Drugs 1996;6:5.

7. Elhami FABW, Esbataita EY. Cervical spine abnormalities associated with Down syndrome. International Orthopaedics 2006;30:284-9.

8. Garin CKR, Sales de Gauzy J, Michel F. La spondylolyse cervicale chez l'enfant. A propos de 4 cas. Revue de la littérature. Rev Chir Orthop Réparatrice Appar Mot 1995;81:626-30.

9. Harwood-Nash DCFCR. Neuroradiology in Infants and Children. Saint Louis, 1976 : $106 \mathrm{p}$.

10. Journel Hubert LD. Spina Bifida. Site électronique Orphanet.1998.

11. Kaiser JAHBA. Imaging of the cervical spine. Spine 1998;23:2701-12.

12. Mitchell LE et al. Spina Bifida. The Lancet 2004;364:1885-95

13. Northrup HVK. Spina bifida and other neural tube defects. Curr Probl Pediatr 2000;30:313-32.

14. Padmanabhan R. Etiology, pathogenesis and prevention of neural tube defects. Congenital Anomalies 2006;46:55-67.

15. Poirier JCM, Poirier I, Baudet J. Leçons d'embryologie humaine. Paris: Maloine, 2005.

16. Takahashi THK, Imagawa K, Asai A, Kuwayama A. Cervical flexion myelopathy associated with cervical Spina Bifida Occulta. Neurol Med Chir 1995;35:392-4.

17. Van Der Put NM. et al. Mutated Methylenetetrahydrolate reductase as a risk factor for spina bifida. The Lancet 1995;346:1070-1. 